\title{
Percent Predicted Peak Expiratory Flow
}

National Cancer Institute

\section{Source}

National Cancer Institute. Percent Predicted Peak Expiratory Flow. NCI Thesaurus. Code C112384.

The maximal flow achieved during the maximally forced expiration initiated at maximum inhalation as a proportion of the predicted normal value. (CDISC) 